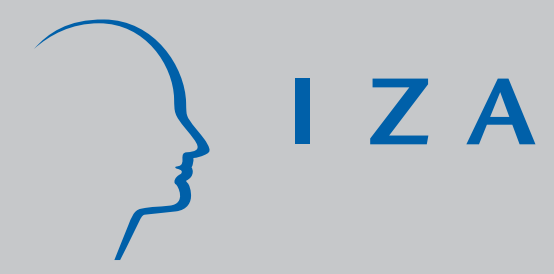

IZA DP No. 2340

Chinese Immigrants in Vancouver: Quo Vadis?

Shibao Guo

Don J. DeVoretz

September 2006 


\title{
Chinese Immigrants in Vancouver: Quo Vadis?
}

\author{
Shibao Guo \\ University of Calgary \\ Don J. DeVoretz \\ RIIM, Simon Fraser University \\ and IZA Bonn \\ Discussion Paper No. 2340 \\ September 2006
}

\author{
IZA \\ P.O. Box 7240 \\ 53072 Bonn \\ Germany \\ Phone: +49-228-3894-0 \\ Fax: +49-228-3894-180 \\ E-mail: iza@iza.org
}

\begin{abstract}
Any opinions expressed here are those of the author(s) and not those of the institute. Research disseminated by IZA may include views on policy, but the institute itself takes no institutional policy positions.

The Institute for the Study of Labor (IZA) in Bonn is a local and virtual international research center and a place of communication between science, politics and business. IZA is an independent nonprofit company supported by Deutsche Post World Net. The center is associated with the University of Bonn and offers a stimulating research environment through its research networks, research support, and visitors and doctoral programs. IZA engages in (i) original and internationally competitive research in all fields of labor economics, (ii) development of policy concepts, and (iii) dissemination of research results and concepts to the interested public.
\end{abstract}

IZA Discussion Papers often represent preliminary work and are circulated to encourage discussion. Citation of such a paper should account for its provisional character. A revised version may be available directly from the author. 
IZA Discussion Paper No. 2340

September 2006

\section{ABSTRACT}

\section{Chinese Immigrants in Vancouver: Quo Vadis?*}

This paper reports findings from a Vancouver study which examines the settlement and adaptation experience of Chinese immigrants in Vancouver. The study reveals that noneconomic reasons, such as the environment, education and citizenship, constituted the primary motivations for Chinese immigrants to move to Canada. Employment and language facilities were the most frequently cited barriers inhibiting their integration into the Vancouver social and economic spheres. Their poor economic performances coupled with the devaluation of both their acquired Chinese education qualifications and labour market experience have hindered integration and increased dissatisfaction with their lives in Canada. Given the logic of our posited triangular migration model we argue that this dissatisfaction will encourage Chinese emigration from Vancouver.

JEL Classification: J15, J61, J60

Keywords: Chinese immigrants, emigration, integration, triangle theory

Corresponding author:

Don J. DeVoretz

RIIM

Simon Fraser University

Burnaby, BC V5A 1 S6

Canada

E-mail: devoretz@sfu.ca

\footnotetext{
* The authors would like to thank both Bryan Yu and Roman Deng for their excellent research assistance and note the Vancouver Centre of Excellence for its financial support. Finally, SUCCESS provided useful contacts and a venue to interview their clients.
} 


\section{Introduction}

The 2001 Census of Canada reveals that Canada's population is becoming increasingly ethno-culturally diverse. It reports that as of May 15, 2001, 18.4\% of Canada's total population was foreign-born and that $13.4 \%$ identified themselves as visible minorities (Statistics Canada, 2003). According to the 2001 census, the Chinese have become the largest visible minority group in Canada, approaching a total of 1,029,400 up from 860,100 in 1996. At the provincial level, Chinese residents comprised the largest proportion of the visible minority populations in British Columbia (44\%), Alberta (30\%), and Saskatchewan (29\%). While many Chinese permanently settle in Canada, an increasing number return "home," be it Hong Kong, Taiwan, or Mainland China. Factors which increase or decrease their level of satisfaction while residing in Canada will ultimately influence their move-stay decision. This paper attempts to identify the salient factors which affected the ability of these Chinese immigrants resident in Vancouver to realize their goals and influence their levels of satisfaction.

This survey based study is part of a large scale research project entitled "The Chinese Leaver-Stayer Project," which examines the underlying forces that influence the "move-stay" decision for Chinese immigrants after their arrival in Canada. The study is comprised of two stages. Stage One seeks to understand the settlement and adaptation experience of Chinese immigrants in Vancouver. Their responses will be compared with those of Chinese immigrants who returned "home" in Stage Two. We employ two distinct methodologies. First, we employed an online survey investigation complemented with in-person questionnaires such that the survey respondents would mimic the salient features of the actual Chinese population in Vancouver circa 2002. ${ }^{1}$

The paper is organized into four parts. The first part provides contextual information and a review of the literature on immigrant circulation. The second section introduces our research methodology. Third, we report the findings of the study. Finally, we conclude with a discussion of the results and their policy implications.

\footnotetext{
${ }^{1}$ The Web-based instrument can be found at www.riim.metropolis.net/surveys/chinesestayers/. The in-person questionnaires used an identical set of questions.
} 


\section{Chinese Emigration to Canada}

To understand the experience of Chinese immigrants, it is important to examine the social and political contexts within which Chinese immigrants lived before their arrival in Canada. According to Li (1998), the majority of the Chinese immigrants originated from three areas: Hong Kong, Taiwan, and China - the focus of this review.

Hong Kong was the primary source of Chinese emigration to Canada after the Second World War (Li, 1998). According to Wong (1992), there have been three major waves of emigration from Hong Kong since the end of the Second World War. The first occurred between 1958 and 1961, owing to dramatic changes in Hong Kong's agriculture sector. The second wave was triggered by a political crisis, the 1967 riot. This riot was a spill-over effect of the Cultural Revolution (1966-1976) in China. Threatened by bombs and political instability, thousands of Hong Kong's elite left for the United States and Canada. The third wave of emigration, described by Wong, began in the 1980s. According to the 1984 SinoBritish Agreement on the future of Hong Kong, the colony would become a special administrative region under the rule of China. Many of the residents who were worried about their future began to leave Hong Kong. A large number of them found homes in Canada. Wong described this latest group of emigrants as “predominantly 'yuppies' - young, educated, middle class professionals” (Wong, 1992, p.4).

China had been isolated from the rest of the world since the People's Republic of China (PRC) was founded in 1949. Until the 1980s direct emigration from China to Canada was relatively small (Li, 1998). The pro-democracy student movement in 1989 became a catalyst as well as a hindrance for the emigration of Chinese people. On the one hand, the event prompted the Canadian government to issue permanent resident status to many Chinese students and scholars who were studying in Canada at that time. On the other hand, the Chinese government tightened the rules to further restrict people's mobility. However, this restriction did not last long. The 1990s witnessed substantial emigration from China to Canada. China’s “open door” policy and economic development resulted in an economic boom in China and a new middle income class. Combined with the relaxed Chinese passport restrictions by the Chinese government, China entered the "emigration phase” (Wallis, 
1998). ${ }^{2}$ Given these developments, the PRC émigrés outnumbered Hong Kong’s and Taiwan's émigrés in 1998, as the PRC became the top source region for immigrants to Canada after 1998 (Citizenship and Immigration Canada, 1999).

Taiwan is a unique case. The influx of emigrants from Taiwan has always been closely related to the island's political instability, particularly with regard to Taiwan's relationship vis-à-vis mainland China (Tseng, 2001). In addition to this concern over political instability, emigration from Taiwan may also be understood as a middle-class response to the problems resulting from discontent with the quality of life under rapid industrialization. According to Kotkin (1993, cited in Tseng, 2001), an estimated 50,000 Taiwanese emigrated between 1985 and 1991, with the United States, Australia, and Canada being the most popular destinations.

\section{Review of Literature}

The move-stay decision has a long history in the migration literature. The original work of Grubel and Scott (1966) and Vanderkamp (1968) on the move-stay decision reflected on the narrow decision that only economically disappointed migrants returned home during their presumably productive years. This neo-classical view argues that migrants were economically rational and only moved if the increase in income exceeded the costs of movement. If their post-movement experience proved this incorrect, then economically failed immigrants returned home to increase their economic gains. ${ }^{3}$

In the 1990's two new branches of migration literature emerged to rationalize the now observed repeated moves of modern immigrants. The first, transnationalism, focused on repeated moves between the sending and one receiving country. Thus migration in a transnational model is described as continuous phenomenon rather than completed event (Ley \& Kobayashi, 2005). Drawing from the experience of returned Hong Kong Chinese immigrants from Canada, Ley and Kobayashi argue that return migration represents one stop in a transnational sojourner's journey. The authors identify economic activity as the recurrent

\footnotetext{
${ }^{2}$ Furthermore, Canada opened its immigration office in Beijing, which processed immigration applications directly from China.
} 
pull to Hong Kong and quality of life as the attraction which draws the family back repeatedly to Canada. Strategic switching between the two identifies appears as they move to separate stations within an extended but unified social field.

We agree with Borjas and Bratsberg (1996) that transnationalism is an incomplete model and we will favour the more strategically rich explanation embedded in the triangular immigration model. ${ }^{4}$ DeVoretz, Ma, and Zhang (2003) earlier adopted a triangular model to explain the movement of Chinese immigrants between Hong Kong, Canada, and the rest of the world (ROW). This model predicts a complex movement pattern of immigrants from sending countries (including Hong Kong) to entrepôt countries (Canada and Australia), and then on to the rest of the world (USA). The authors argue that immigrants initially choose an entrepôt country like Canada because it supplies subsidized human capital (language training, education) and other free public goods (a passport, good government, etc.). However, the authors continue to argue that, after the initial move to the entrepôt country, these immigrants face three future choices: (i) staying permanently in the new entrepôt country (Canada), (ii) returning to the origin country (Hong Kong or PRC), or (iii) moving on to a third country (U.S.A. or the rest of the world). This triangular model further predicts that immigrants will stay in the entrepôt destination (Canada) or move on depending on their economic satisfaction while resident in the entrepôt country relative to other possible destinations given their new citizenship status. We will use the theoretical arguments of the triangular model to frame our survey questions and to analyze our findings when we assess the level of satisfaction of the resident Chinese in Vancouver and their prospects of remaining in Canada.

\section{Research Methodology}

This research adopts a questionnaire approach. Earlier work by DeVoretz, Ma and Zhang (2003) and Ma and Tian (2006) on this topic clearly stated the limitations of an econometric analysis based solely on census data. Thus, the raison d'être for a web-based

\footnotetext{
${ }^{3}$ Neo-classical theory allowed return migration after retirement since pensions earned in the host country often would lead to greater disposable income in the sending country so this return movement was deemed rational.

${ }^{4}$ Borjas and Bratsberg (1996) argue that return migration could be rational in a Neo-Classical model if we note that immigrants acquire skills after moving and may exploit these skills by returning home.
} 
questionnaire approach derives from its capability to explore in depth the motivations that might ultimately condition the decision to stay or move and to maximize the number of responses in a reasonably short time. There are four parts to the questionnaire: i) basic demographic information, ii) a description of the motivations for immigrating to Canada, iii) the Canadian experience of Chinese immigrants including their level of satisfaction with Canada, and iv) concluding remarks.

Part one seeks to understand the participants in terms of their age, gender, citizenship, immigrant entry category, and their educational background. Part two aims to examine the Chinese immigrants' motivations for moving to Canada, and whether they have achieved their original goals they had prior to immigrating to Canada. Part three is the core of the questionnaire, which addresses their integration experience in Canada, including their economic, social, cultural, and language integration, and their experience with government and non-government organizations. The last part includes only open-ended questions which invite participants to comment on changes they feel need to be made in order to help immigrants integrate into Canadian society more effectively. The questionnaire was made available in both English and Chinese.

The sample that was ultimately drawn covered 322 completed questionnaires for those reported to be Vancouver residents, with 174 drawn from the web source and the remaining 148 the result of in-person questionnaires up to August 17th, 2005. In order to make this sample representative, we allowed our sample to mimic the main characteristics of the economically active Chinese-born population resident in Vancouver as reported in the 2001 census. ${ }^{5}$ The response rate for the web based survey is not possible to calculate directly since presumably everyone is eligible to fill in the form but of course they first must be aware of the form's existence. A proxy for the response rate is the number of questionnaires that were "opened" on the website but not completed. This ratio was $30 \%$ indicating that of those who self selected to open the questionnaire 30\% actually completed the questionnaire

\footnotetext{
${ }^{5}$ The economically active is defined as those respondents who were aged 20 to 65 and were currently in the Vancouver labour force.
} 
on line for all questions posed. ${ }^{6}$ In addition, of the 148 face to face administed questionnaires the response rate was $100 \%{ }^{7}$

One bias inherent in this web based approach is that the computer literate web based population is young and highly educated. In order to minimize this bias we, as earlier noted, we compared our original web based sample to the Chinese population as reported in the 2001 Canadian census and filled in the gaps with in-person questionnaires. Thus the survey while small is representative of the Chinese immigrant population in Vancouver circa 2001.

\section{Research Findings}

\section{Sample Design}

This survey is strategic in nature; namely we seek to understand the motivations of recent Vancouver Chinese immigrants to consider staying or leaving. In fact, as Figure 1 portrays, we are oversampling the economically active Chinese immigrant population residents in Vancouver circa 2004-2005 since over 90\% of our surveyed population are aged 20 to 60.

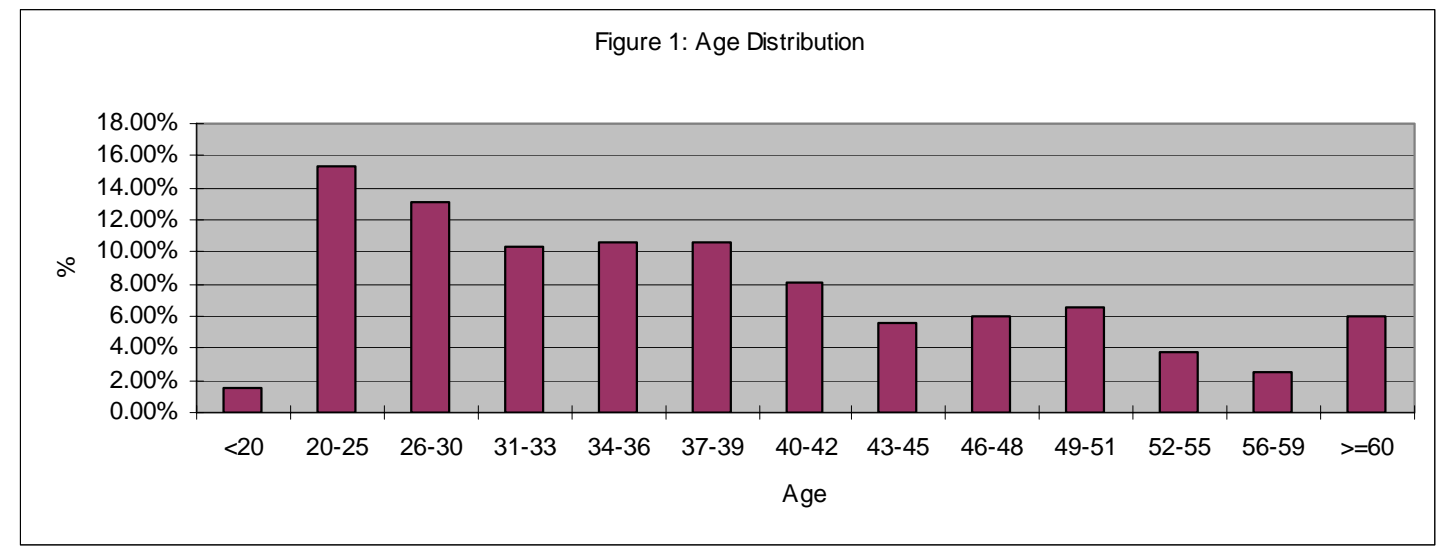

\footnotetext{
${ }^{6}$ The exact breakdown of the response ratios by linguistic type of questionnaire was (61 Chinese +249 English) / (222 Chinese + 813 English).

${ }^{7}$ We completed 43 questionnaires at SUCCESS and the remaining 105 at MOSAIC, ISS, and Surrey-Delta Immigrant Services. All these agencies arranged these interviews as a by product of their citizenship or other integration classes.
} 
In addition, as Figure 2 demonstrates, over $60 \%$ of the sample was comprised of males and $40 \%$ females, which again mimics the gender distribution of Vancouver's Chinese labour force circa 2001 and fulfills our goal of emphasizing the economically active Chinese immigrant population. ${ }^{8}$

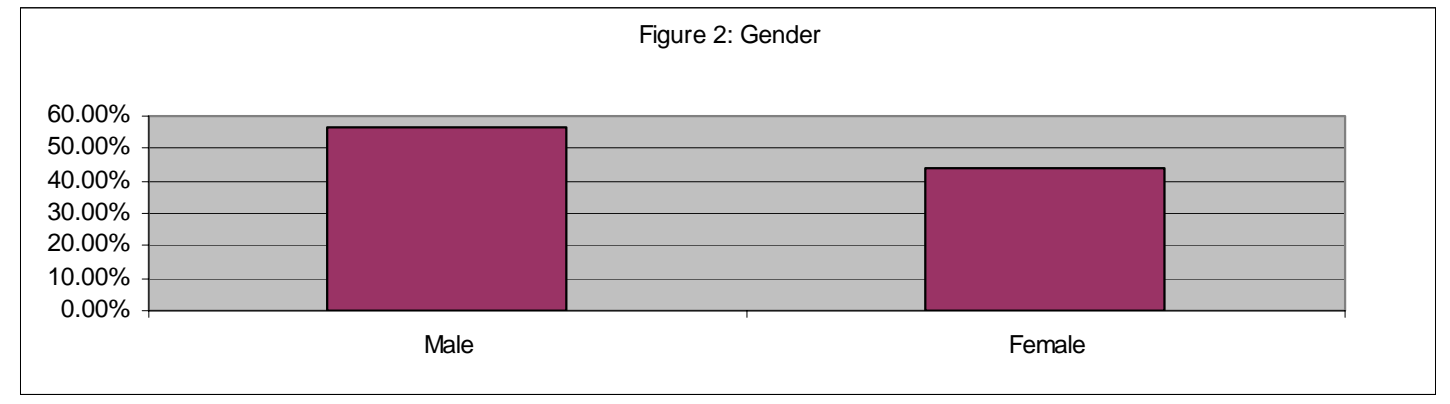

Place of birth is an essential conditioner in the move-stay decision since the level of development in the origin country relative to Canada will often entice immigrants to return (DeVoretz, Ma, and Zhang 2003). Moreover, an historical analysis of Chinese immigrants who leave Canada suggests that the majority who leave are from the PRC and they leave in the first five years. ${ }^{9}$ Thus, to capture that portion of the Vancouver Chinese population that is most prone to leave, we would like to over sample recent PRC immigrant arrivals. Figure 3 demonstrates that this survey sample fulfills this goal since mainland China (PRC) arrivals represent 58\% of the sample with Hong Kong (27\%) and Taiwan (10.4\%) providing another $33 \%$ by place of arrival. ${ }^{10}$

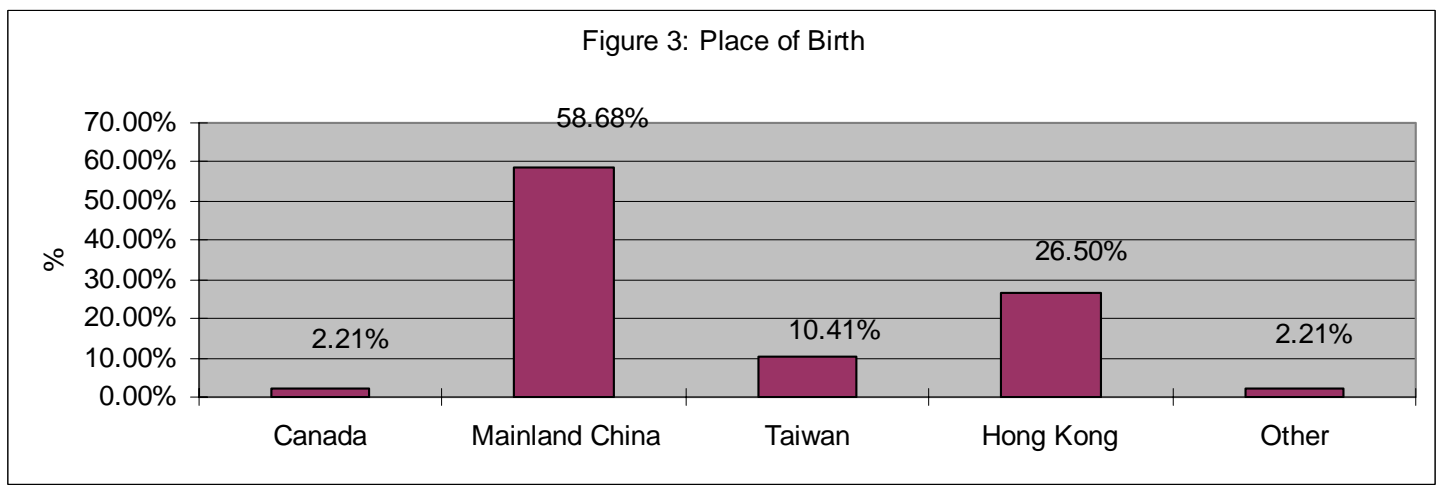

\footnotetext{
${ }^{8}$ See Statistics Canada (2003).

${ }^{9}$ See Abdurrahmna and Robinson (2006).

${ }^{10}$ Between 1997 and 2004, PRC Chinese immigrants represented 18.4\% of the Canadian immigrant inflow.
} 
In sum, Figures 1 to 3 report that the survey population reflects those we aimed to target, namely the economically active recent Chinese immigrant arrivals to Vancouver who are most prone to leave.

\section{Sample Statistics}

Marital status and visa status may also condition the immigrant's degree of integration and hence satisfaction with Vancouver and these characteristics for the Chinese sample population in Vancouver are reported in Figures 4 and 5.

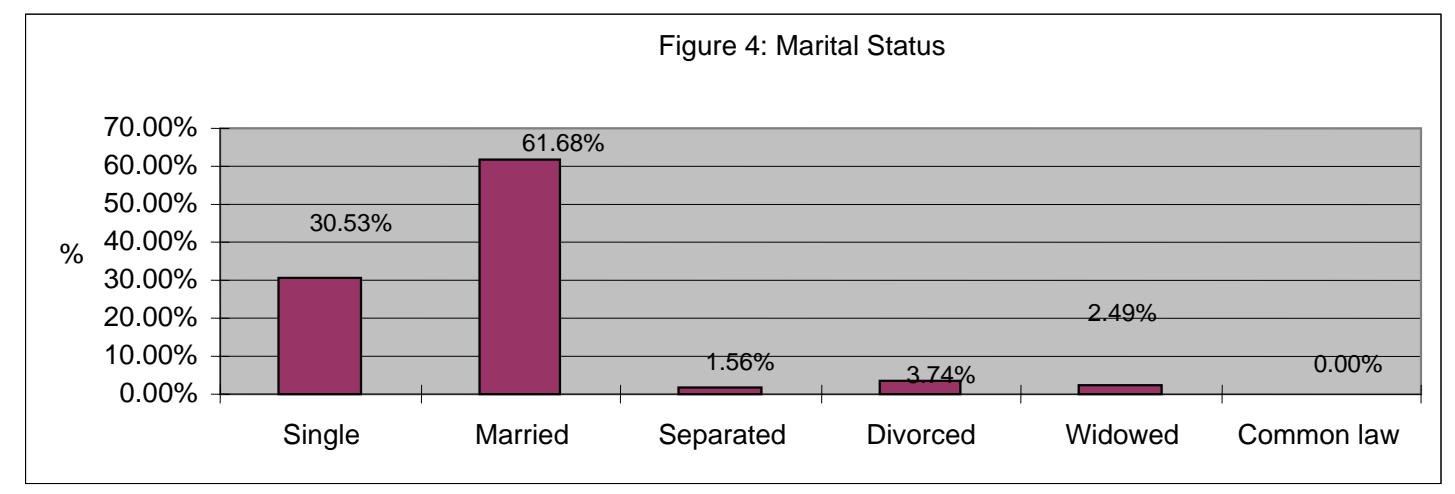

The majority of our survey population is married (62\%) with permanent residence status in Canada since they are either Canadian citizens (48\%) or landed immigrants (44\%). These two characteristics, married with Canadian citizenship should positively influence the sampled households' economic outcomes and enhance integration if the Chinese immigrant community in Vancouver follows the general Canadian immigrant population (DeVoretz \& Pivnenko, 2006). 


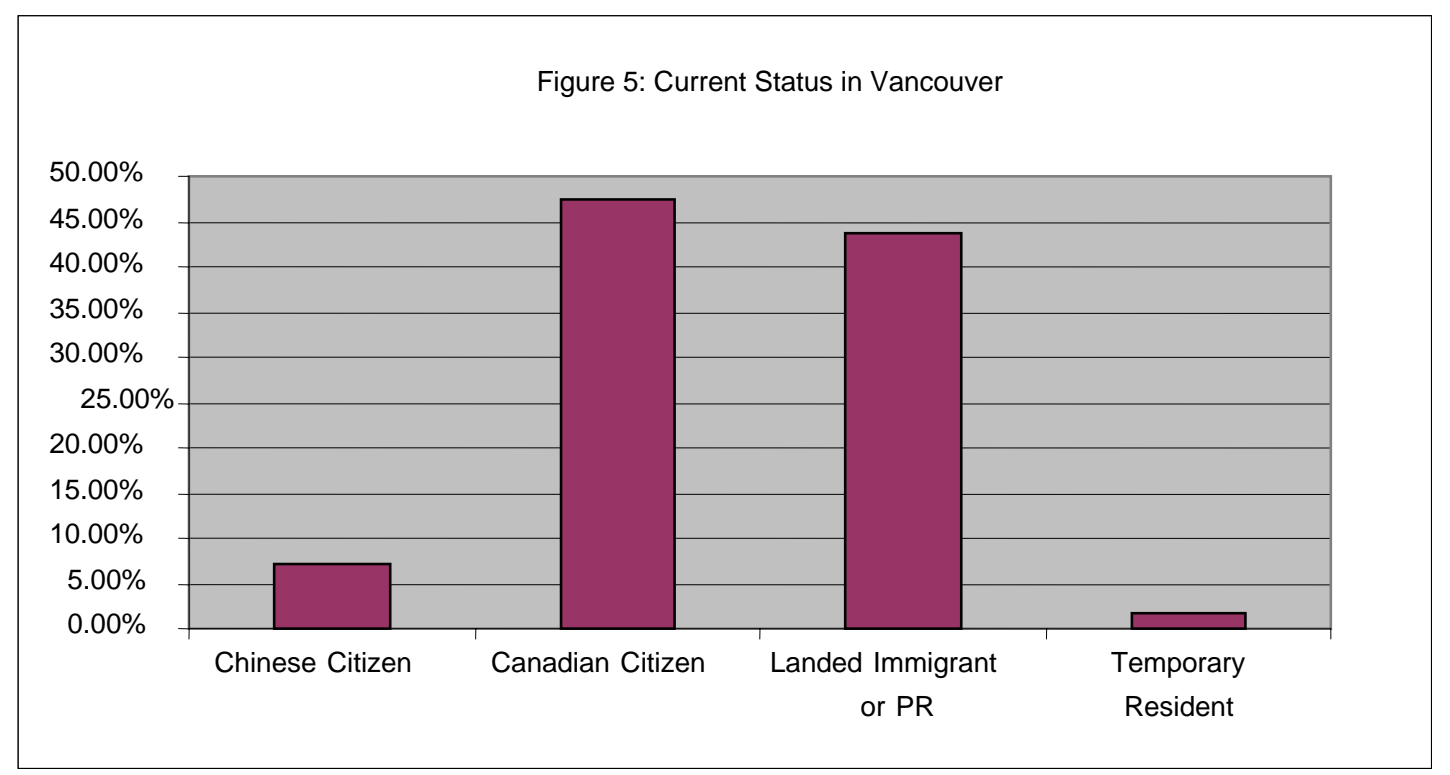

The length of time in residence in Canada (Figure 6) for our sampled population is, on average, short (7 years, 5 months) and this short residency may hinder integration. Nonetheless, the vast majority of the Chinese immigrants sampled (75\%) have been in residence greater than three years, which would explain this relatively high rate of citizenship acquisition. $^{11}$

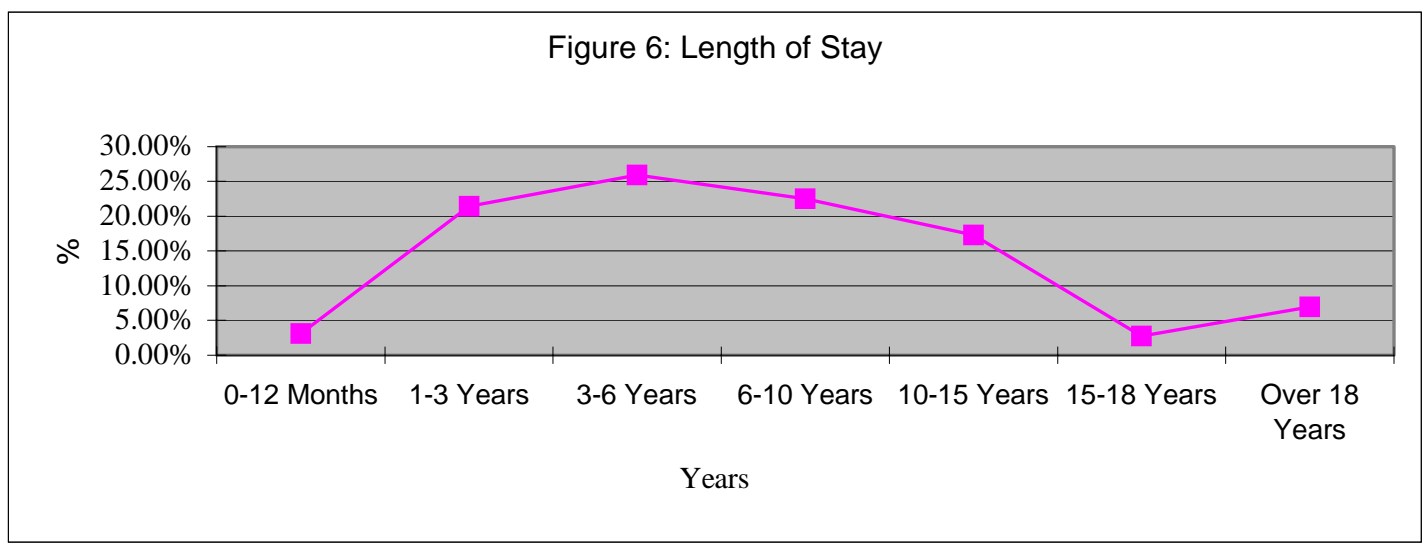

\footnotetext{
${ }^{11}$ Three years of continuous residence qualifies a permanent Canadian immigrant to apply for citizenship. In practice, citizenship acquisition requires at least four years in residence (DeVoretz \& Pivnenko, 2006)
} 


\section{Conditions Prior to and at Arrival in Canada}

Why did this sampled Chinese group of immigrants move to Vancouver? The answer to this question can ultimately shed light on the degree of satisfaction experienced by recent Chinese arrivals to Vancouver. Since our sampled group is young and married and living in Canada with permanent visa status or citizenship, we would anticipate that their motives to move were long term and perhaps economic in nature. An inspection of Figure 7 indicates that, in fact, economic motivations (i.e. a higher paying job, greater job security or promotion) taken collectively only motivated $37 \%$ of the recent arrivals. Acquiring Canadian citizenship (39.7\%) and Canada’s pleasant physical environment (51.7\%) were clearly the strongest forces motivating a move to Vancouver. In addition, the immigrant's intentions to acquire further education (25.5\%) and facilitate their children's education acquisition (32.1\%) were also incentives to move to Vancouver. In sum, what economists would label as tax financed public goods - the environment, education and citizenship were the stated primary goods which attracted these immigrants to Vancouver. This is a unique finding and in the concluding section we will explore the implications of this non-economic motivation in the context of the triangular model outlined above.

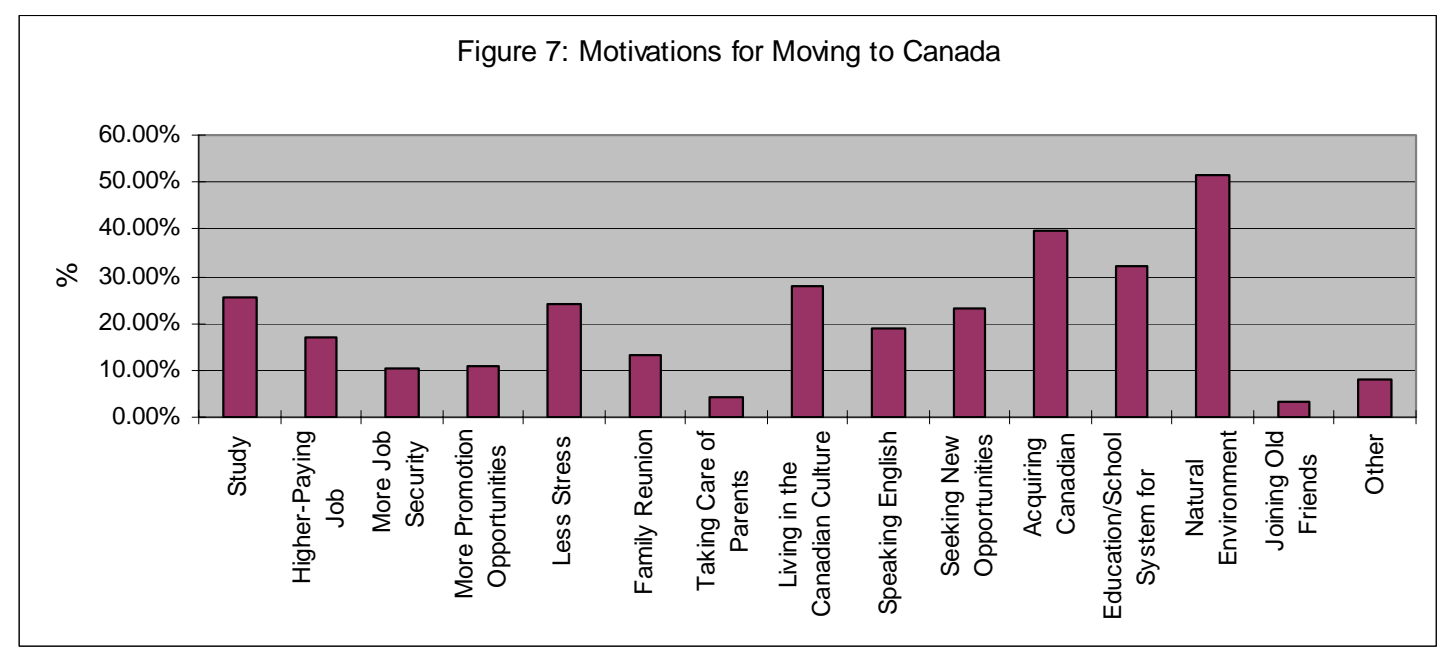

Given these motivations to move and remembering the average length of stay of this surveyed population was seven years, did these immigrants realize their defined goals? 


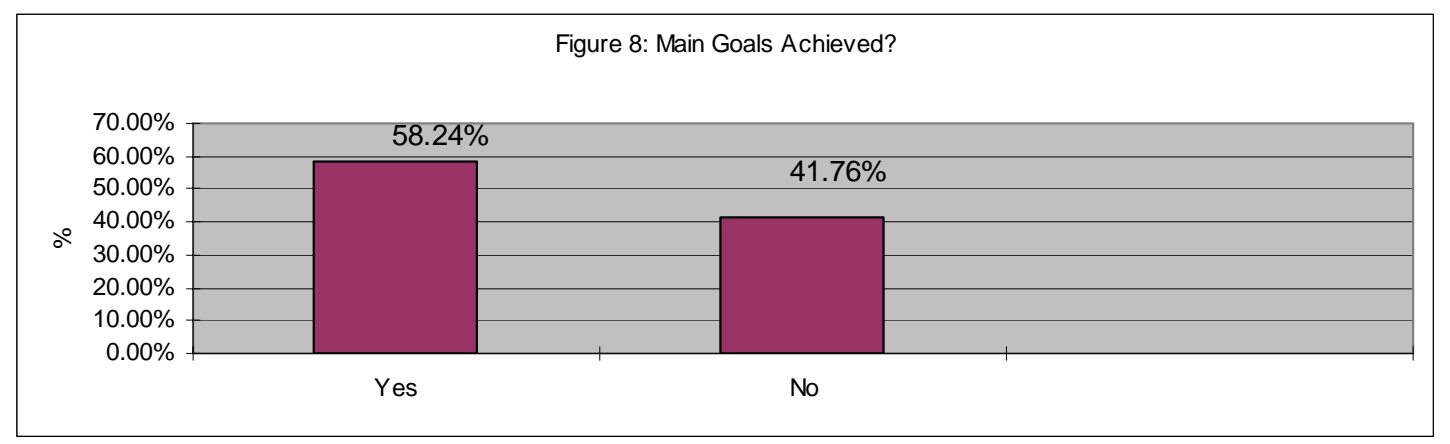

A majority (58.2\%) did indicate according to Figure 8 that they had achieved their goals with $42 \%$ indicating disappointment in not achieving their goals. Of those who did not achieve their goals, over $70 \%$ rated their chances of achieving their remaining goals as uncertain or slim (Figure 9).

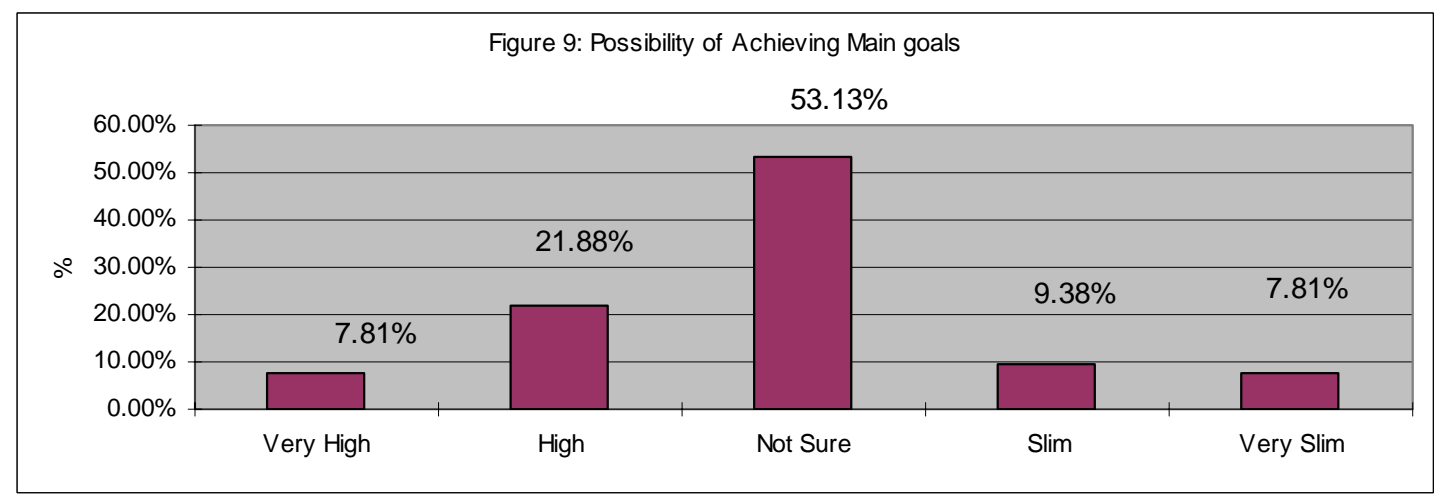

Given this uncertain status of achieving their goals, it is not surprising that $74 \%$ of the surveyed population encountered difficulties after arrival (Figure 10), with language and employment being the most frequently cited barriers. 


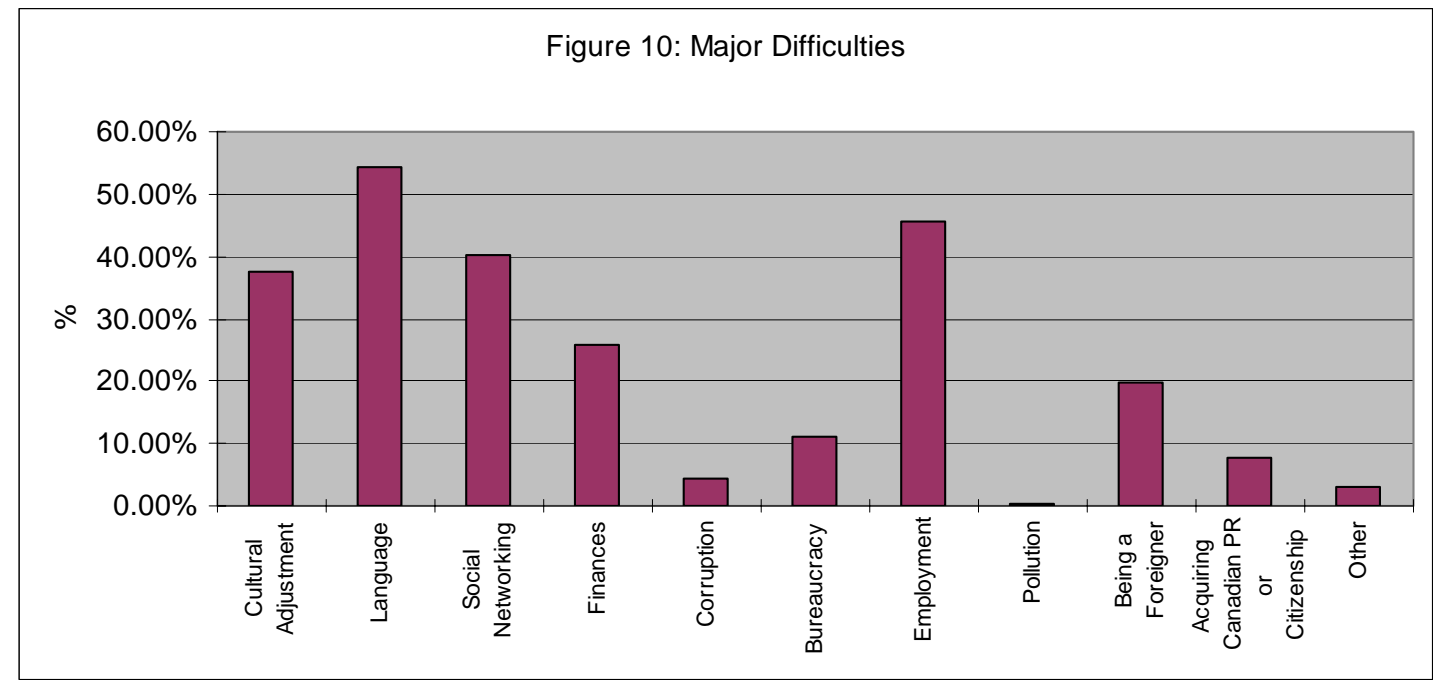

Given that employment was viewed as one of the major difficulties encountered by these surveyed immigrants, we explored the nature of their employment difficulties in detail below.

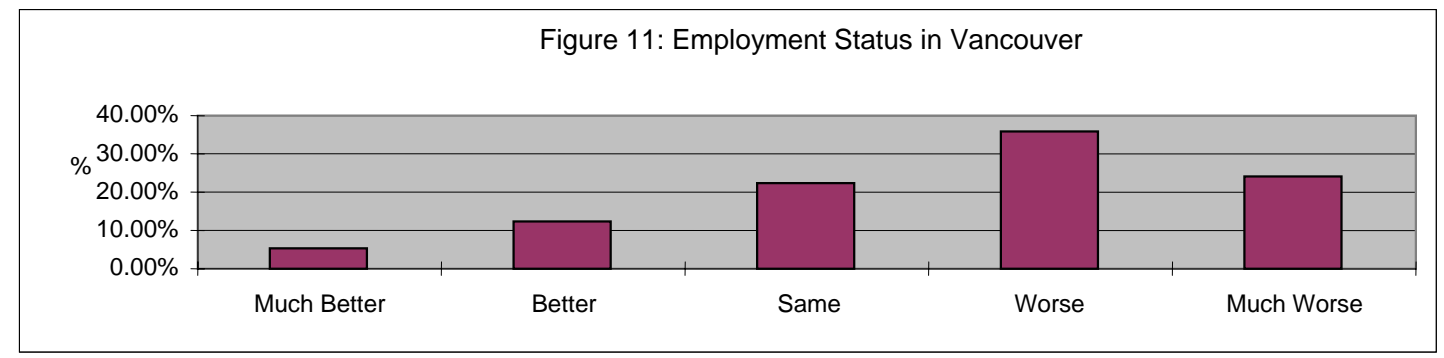

Over $60 \%$ of the Vancouver surveyed Chinese population indicated that their employment situation in Canada was worse than in Hong Kong, Taiwan, and Mainland China and only a minority (17\%) perceived it as better (Figure 11). This finding is noteworthy since our data report that $72.5 \%$ of our survey population have post-secondary education, among whom $26.7 \%$ have either a master's or doctoral degrees. Moreover, the majority of our surveyed respondents felt that their Chinese labour market experience was not helpful (Figure 12) in the Vancouver labour market. 


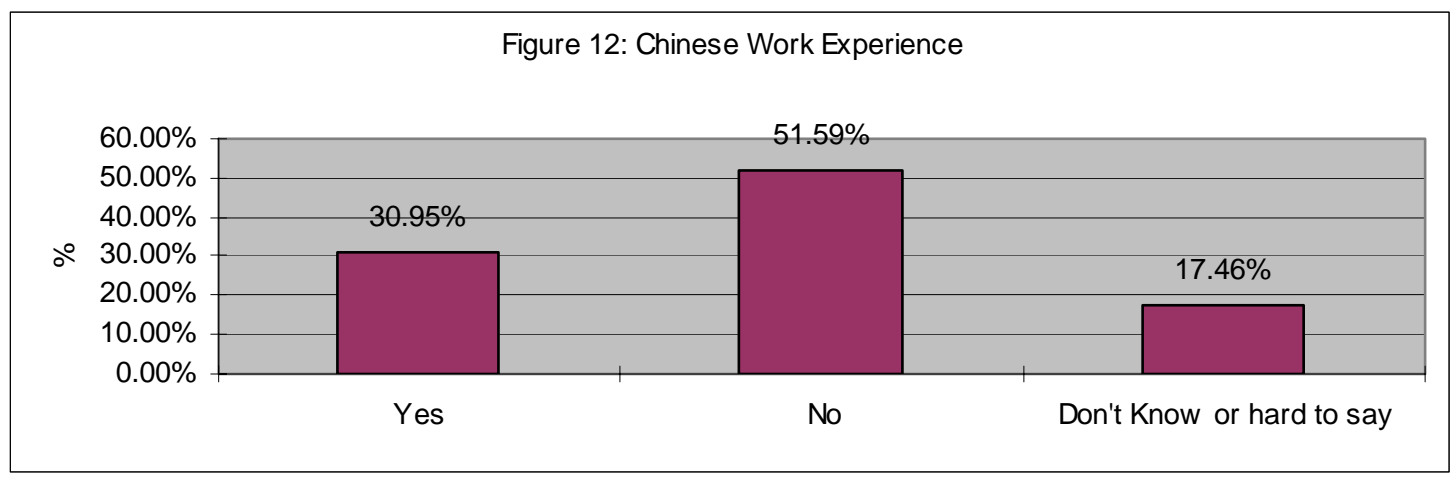

Table 1: Income Distribution in Vancouver (CND \$)

Household Income in Canada (CND \$ 2005)

\begin{tabular}{ll}
\hline Up to 20000 & $43.7 \%$ \\
20001 to 31000 & $15.9 \%$ \\
31001 to 46000 & $17.1 \%$ \\
46001 to 62000 & $8.2 \%$ \\
62001 to 78000 & $4.45 \%$ \\
Over 78000 & $10.6 \%$ \\
\hline
\end{tabular}

These pessimistic responses are mirrored in their reported household incomes (Table 1) with over $60 \%$ of the surveyed households reporting earnings of less than $\$ 31,000$ with $44 \%$ reporting poverty level incomes of less than $\$ 20,000 .^{12}$

Even more pressing than this lack of employment integration was the cited language barriers reported by the Chinese in Figure 10. We also explore this impediment in detail below.

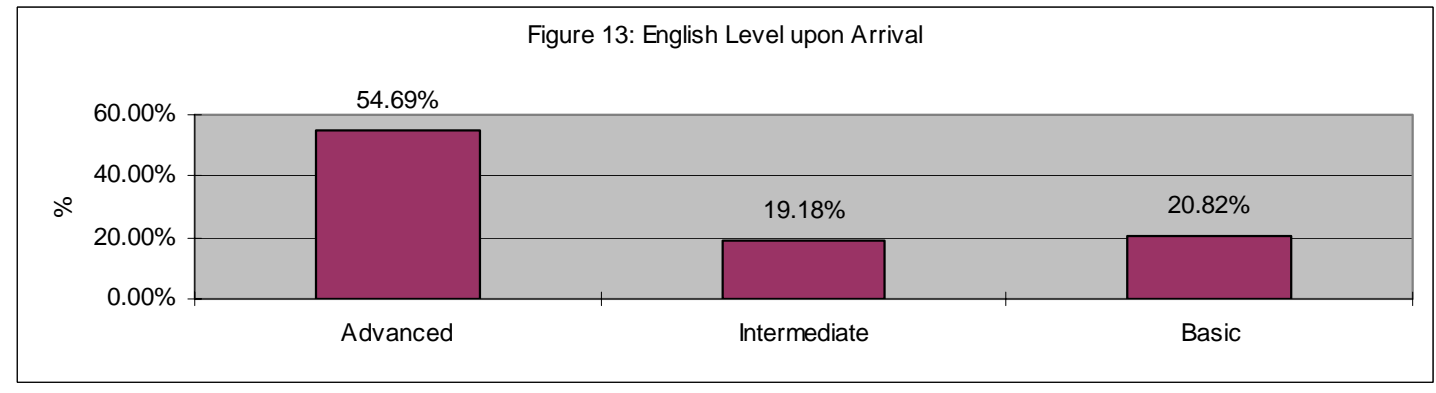

\footnotetext{
${ }^{12}$ These reported income levels of this highly skilled group is less than for refugees in Canada (Biser, DeVoretz \& Pivnenko, 2005).
} 
Given the stated linguistic difficulties noted in Figure 10, the results reported in Figure 13 seem puzzling with 55\% of the surveyed Chinese stating that at the time of the survey they had advanced level English skills.

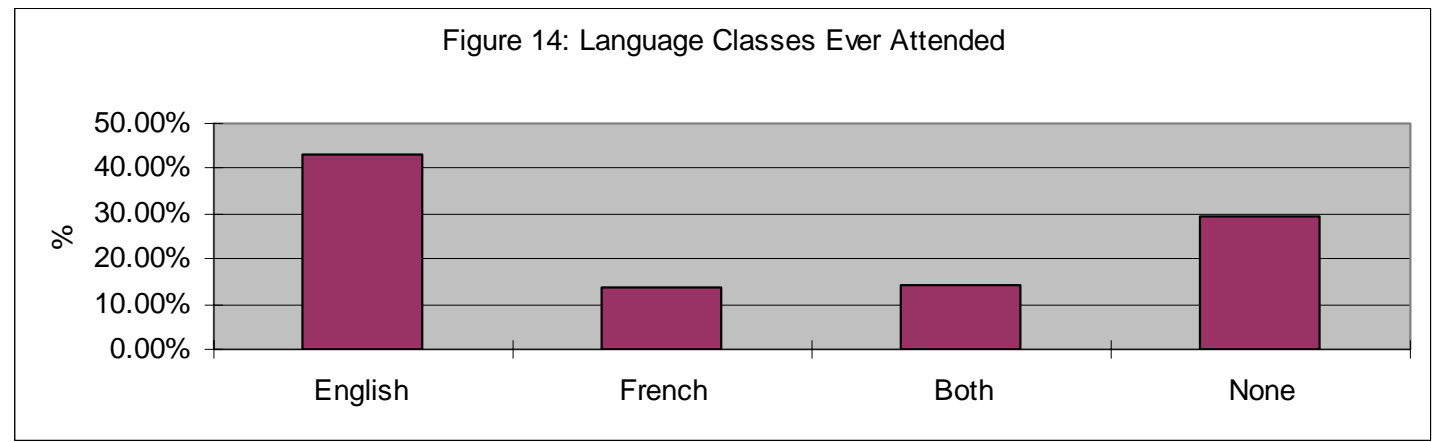

Figure 14 reports a high number of Chinese immigrants attending English classes after arrival (70\%) and confirms our suspicions that their language skills were not as stated as in Figure 13, or their English (e.g., Chinese accent) was not acceptable in the host society.

\section{Immigrant Assessment of Vancouver}

Given their stated motivations to move and their linguistic and employment difficulties encountered after arrival in Vancouver, what was this group's overall assessment of Vancouver when compared to their expectations prior to arrival? In other words was there a significant gap between expectations and reality?

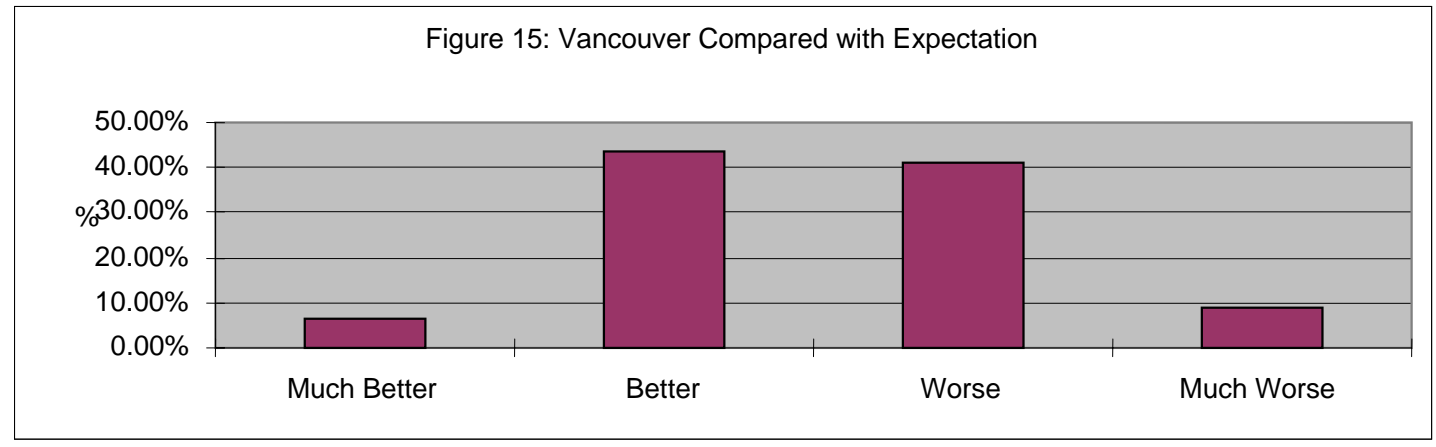

The even split between those who felt they were better or worse off (Figure 15) after arrival reflects their reported employment and linguistic experiences in Vancouver. 


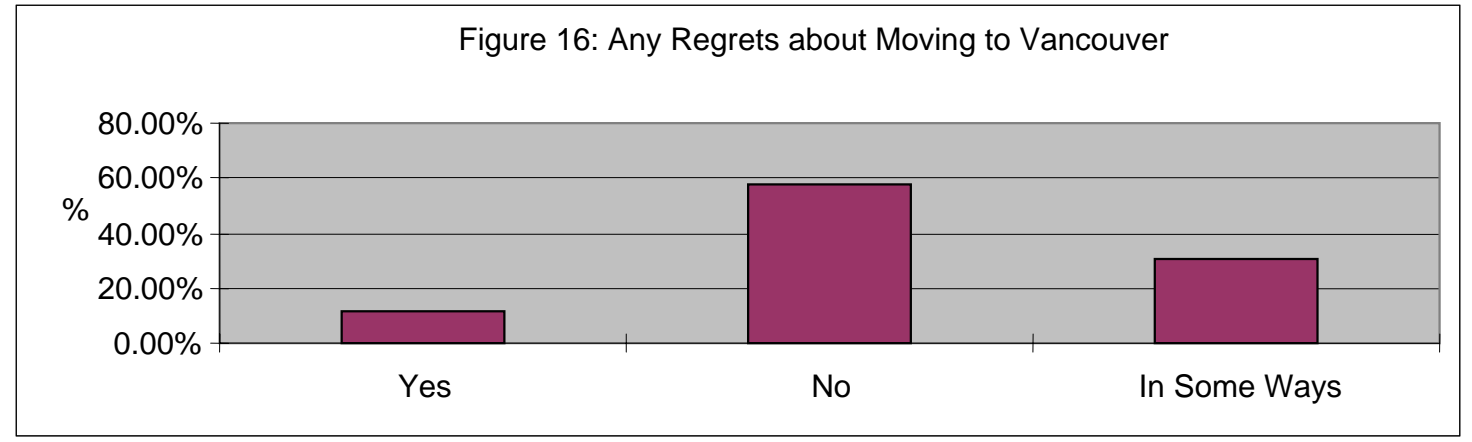

How did this reported gap between expectations and reality translate into a summary statement about any regrets about moving to Vancouver? The results in Figure 16 which report stated regrets are surprising given the often stated gap in expectations and reality for their Vancouver integration experience since only 11.7\% of the respondents felt any regrets about moving to Vancouver.

Nonetheless, even given this lack of regret about moving to Canada, the Chinese sought help from friends and not NGOs or governments (Table 2). However, if they did visit a Vancouver NGO, the majority (60\% of visits) visited mainly a uni-cultural Chinese organization (S.U.C.C.E.S.S.) primarily to find a job (60\% of cases).

Table 2: Distribution of Organizations Visited in Vancouver

\begin{tabular}{ll}
\hline Organization(s) Visited & $n=188$ \\
\hline Burnaby Multicultural Society & $5.9 \%$ \\
Family Services of Greater Vancouver & $0.00 \%$ \\
ISS & $12.2 \%$ \\
MOSAIC & $6.4 \%$ \\
North Shore Multicultural Society & $2.7 \%$ \\
SUCCESS & $59.6 \%$ \\
Taiwanese Canadian Cultural Society & $8.0 \%$ \\
Other & $5.9 \%$ \\
\hline
\end{tabular}

\section{Logistic Regression Analysis}

In order to predict which groups of Vancouver resident Chinese are the most likely to experience dissatisfaction and possibly leave Vancouver, we offer a simulation exercise based on a logit analysis. The intuition at this point is to look at several questions which would 
indicate the subject's inherent willingness to stay or leave Vancouver. Next, we attempt through logit analysis to find what elements reported in the survey influence the respondents' answers to the question under consideration. ${ }^{13}$ For example, question 2.6, or: "Have you achieved your main goals in Canada?”
a. Yes
b. No
c. Don't know or hard to say

allows an analysis of the determinants of the log odds of answering yes or no to this question.

We argue that the answer to question 2.6 takes the form of logistic function which can be expressed as the probability of observing a positive response (or yes) from a representative sample of Chinese immigrant in Vancouver conditioned on a vector of independent explanatory variables. ${ }^{14}$ The independent variables that condition the log odds of answering yes are age, education (number of years of education), Canadian education, number of years in Canada and the income level of the household. The vector of parameters was estimated with the Maximum Likelihood Method.

We report the results of the first stage of this analysis below in Table 3 with the significant coefficients denoted in bold face and the variables defined in the Appendix.

\footnotetext{
${ }^{13}$ We thank James Kwan for this insight.

${ }^{14}$ The logistic function is $P\left(Y_{i}=1 \mid X_{i}\right)=\frac{\exp \left(X_{i} \beta\right)}{1+\exp \left(X_{i} \beta\right)}$ where $P\left(Y_{i}=1 \mid X_{i}\right)$ is the probability of observing a positive response from a sampled Chinese immigrant in Vancouver conditioned on a vector of explanatory variables $X_{i}$, which may influence the likelihood of a positive or negative answer.
} 
Table 3. Did Chinese Immigrants achieve their goals whilst in Canada: A Logit analysis of question 2.6

\begin{tabular}{|c|c|c|c|c|c|c|}
\hline Variable & Coef. & Std. Err. & $\mathbf{z}$ & $\mathbf{P}>|\mathbf{z}|$ & \multicolumn{2}{|c|}{ [95\% Conf. Interval] } \\
\hline Gender & -.026575 & .3430713 & -0.08 & 0.938 & -.698983 & .6458316 \\
\hline Age & .0915444 & .022728 & 4.03 & .0 .000 & .0469982 & 1360906 \\
\hline $\begin{array}{l}\text { Marital } \\
\text { state }\end{array}$ & -1.07540 & .442433 & -2.43 & 0.015 & -1.94256 & -.2082543 \\
\hline $\begin{array}{l}\text { Education } \\
\text { Level }\end{array}$ & -.129855 & .1483841 & -0.88 & 0.382 & -.420682 & .1609725 \\
\hline $\begin{array}{l}\text { Canadian } \\
\text { Education }\end{array}$ & -.983042 & .3580266 & -2.75 & 0.006 & -1.68476 & -.2813229 \\
\hline $\begin{array}{ll}\text { Length } & \text { of } \\
\text { Stay } & \text { in } \\
\text { Canada } & \end{array}$ & -.003608 & .0058829 & -0.61 & 0.540 & -.015138 & .0079216 \\
\hline $\begin{array}{l}\text { Household } \\
\text { income }\end{array}$ & .0000398 & $9.69 e-06$ & 4.11 & 0.000 & .0000208 & .0000588 \\
\hline Constant & -1.4748 & 1.052621 & -1.40 & 0.161 & -3.5379 & .5882988 \\
\hline
\end{tabular}

Notes: Number of observations $=203$, Pseudo $R^{2}=0.2051$

Age, marital status, educational location and household income all significantly conditioned the log odds of answering question 2.6. ${ }^{15}$ The older an immigrant (age) and the greater his/her household income, the greater the log odds of having achieved his/her goals whilst in Canada. On the other hand, if the individual was unmarried or obtained a non Canadian education the log odds of achieving his/her goals in Canada was lower. ${ }^{16}$

We further explore the respondents' answers to question 2.6 by analyzing through a logistic analysis the answer to question 2.6.2:

2.6.2 If you answered question 2.6 "no," what is the possibility of achieving the main goals you set up for yourself before moving to Canada?

The possible answers were as follows:
a. Very high
b. High
c. Not sure
d. Slim
e. Very slim

In this second stage for ease of analysis we regroup the answers to question 2.6.2 into three categories: (1) very high and high (2) not sure and (3) slim and very slim. ${ }^{17}$ Now we perform a multi-nominal logit to determine which of above variables predict the log-odds of being in categories 1 to 3 . In effect, this model attempts to predict which of these variables

\footnotetext{
${ }^{15}$ If the null hypothesis is rejected then the coefficient is not equal to zero. For the coefficient to be significant than the $\mathrm{z}$ value should be greater than .85 .

${ }^{16}$ Note a negative coefficient just indicates a reduction in the log odds of responding question to question 2.6.

${ }^{17}$ This regrouping yielded allowed us to have sufficient cell sizes.
} 
significantly changed the log odds of influencing the immigrant's chances of achieving their unrealized goals.

We divided our analysis into those Chinese who felt optimistic about achieving their goals and then carried out the same analysis for those Chinese who stated they were pessimistic about achieving their goals. We used the same variables as those reported in table 3 and the majority of these variables (unreported) were not significantly related to either being very optimistic about achieving their goals or very pessimistic about achieving their goals. However, an increase in household income did significantly increase the log odds of stating that the likelihood of being successful in the future was either very high or high. On the other hand, as the respondent aged the log odds of stating that the likelihood of success was slim grew significantly.

A second crucial question which could reveal the Chinese resident's satisfaction and ultimate intention to stay in Vancouver or leave appears in the survey as:

"Compared with your situation in China, how would you describe your social life in

\section{Canada?"}

With the following possible answers:
a. Much better
b. Better
c. Same
d. Worse
e. Much worse

Which for purposes of our logit analysis were regrouped into these three groups:
1. Much Better/Better
2. Same
3. Worse/Much worse 
Table 4. Multinomial Logit Analysis of Questions 3.11

\begin{tabular}{|c|c|c|c|c|c|c|}
\hline Variable & Coef. & Std. Err. & $\mathbf{Z}$ & $\mathbf{P}>|\mathbf{z}|$ & \multicolumn{2}{|c|}{ [95\% Conf. Interval] } \\
\hline \multicolumn{7}{|c|}{ Panel A. Comparison of category 2 to 1} \\
\hline Gender & .0094964 & .3618503 & 0.03 & 0.979 & -.6997171 & .7187098 \\
\hline Age & -.0492663 & .0201535 & -2.44 & 0.015 & -.0887665 & -.0097661 \\
\hline Marital State & .2717483 & .2658162 & 1.02 & 0.307 & -.2492419 & .7927385 \\
\hline $\begin{array}{l}\text { Educational } \\
\text { level }\end{array}$ & .3031285 & .1535447 & 1.97 & 0.048 & .0021864 & .6040706 \\
\hline $\begin{array}{l}\text { Canadian } \\
\text { education }\end{array}$ & .5431739 & .3610247 & 1.50 & 0.132 & -.1644214 & 1.250769 \\
\hline $\begin{array}{l}\text { Length of } \\
\text { stay }\end{array}$ & -.0042336 & .00564 & -0.75 & 0.453 & -.0152878 & .0068206 \\
\hline $\begin{array}{l}\text { Household } \\
\text { income }\end{array}$ & $-6.17 e-07$ & $9.23 e-06$ & -0.07 & 0.947 & -.0000187 & .0000175 \\
\hline constant & -.4858698 & 1.18561 & -0.41 & 0.682 & -2.809623 & 1.837883 \\
\hline \multicolumn{7}{|c|}{ Panel B: Comparison of category 2 to 3} \\
\hline Gender & -.1985158 & .4321508 & -0.46 & 0.646 & -1.045516 & .6484843 \\
\hline Age & -.1121822 & .0292965 & -3.83 & 0.000 & -.1696023 & -.0547621 \\
\hline $\begin{array}{l}\text { Marital } \\
\text { State }\end{array}$ & .5432876 & .3374052 & 1.61 & 0.107 & -.1180144 & 1.20459 \\
\hline $\begin{array}{l}\text { Educational } \\
\text { level }\end{array}$ & .2239037 & 190089 & 1.18 & 0.239 & -.1486639 & .5964713 \\
\hline $\begin{array}{l}\text { Canadian } \\
\text { education }\end{array}$ & .525899 & .4407227 & 1.19 & 0.233 & -.3379015 & 1.3897 \\
\hline $\begin{array}{l}\text { Length of } \\
\text { stay }\end{array}$ & -.0038618 & .0060732 & -0.64 & 0.525 & -.015765 & .0080414 \\
\hline $\begin{array}{l}\text { Household } \\
\text { income }\end{array}$ & 6.63e-06 & .0000107 & 0.62 & 0.534 & -.0000143 & 0000275 \\
\hline Constant & 1.020565 & 1.358957 & 0.75 & 0.453 & -1.642942 & 3.684073 \\
\hline
\end{tabular}

Notes: $\mathrm{N}=322$ Pseudo $\mathrm{R}^{2}=0.08$

Table 4 Panel A reports the significant effect (in bold) of variables collected from our Vancouver sample on the log odds of being in category 2 (the same) versus 1 (much better/better). The older the respondent was in the survey period, the less likely would be the log odds that this person would report that he or she was much better or better off socially in Vancouver. If the respondent had a high educational level or obtained his/her education in Canada the log odds of being socially satisfied in Vancouver increased significantly. 
Panel B where indicates that the log odds of moving from being much worse (or worse) socially in Canada relative to an identical standing vis-à-vis China is significantly negatively affected by the respondent's age, and positively affected by being married.

In sum, this logit analysis indicates that well know sample characterisitics including age, education, marital status influence the Vancouver Chinese resident population's degree of integration.

\section{Suggestions from Immigrants}

Recognizing the fact that the majority of questions we posed offered limited space for participants to express their opinions in detail, we included two open-ended questions in the questionnaire:

1) From your experience, what could the Canadian Government do to help new Chinese immigrants integrate into Canadian society more effectively?

2) Is there anything both the Canadian and Chinese governments could do in cooperation to better help Chinese immigrants?

We received 145 entries to these open ended questions. Responses concerning what the Canadian government can do are organized into two major categories: pre-landing immigration and post-landing settlement actions. Many people suggested that immigrant settlement should start before immigrants have landed in Canada. One respondent said: "[The] Canadian government should go to China to let those who want to emigrate to Canada better understand Canada." Another suggested to: "Hold classes in China to help immigrants adjust to the life in Canada." Still another commented that Canada should: "Help immigrants to know the difference between the two countries from all aspects as early as possible."

Some people felt misinformed about Canada before applying for immigration. Therefore, many of them suggested that the Canadian government: "Provide Chinese people [with] a more realistic view of Canada." "[The] Canadian government should tell people in advance of all difficulties they may encounter in Canada in the near future and help them 
prepare for it." And "Inform potential immigrants that their qualifications may not be recognized by [the] Canadian society."

A few respondents also commented on the application process. One respondent suggested to: "Speed up the processing time of immigration applications.” Another one said: "Improve immigration application and management" while others suggested to: "Encourage international graduates to immigrate to Canada.”

Suggestions concerning post-landing settlement are mainly concentrated in four areas: 1) employment, 2) the recognition of Chinese credentials and work experience, 3) the provision of English training programs, and 4) settlement services. In particular, many surveyed Chinese are concerned with their unemployment and underemployment situations. Some people suggested government intervention to: "Provide more training and employment opportunities," or to: "Fund immigrants to find a job or start [their] own business."

Some respondents also made concrete suggestions, such as: "Create and introduce more internship or co-op opportunities so that new immigrants can obtain their first North American experience to find a job they like," or: "Help local companies to hire new immigrants by providing (a) funding/incentive. “

Many respondents attributed their unemployment and underemployment situations to the non-recognition of their Chinese credentials and work experience. Some commented that: "Immigrants are underemployed because their educational levels are not recognized;" or that the lack of: “'Canadian experience' is a racist excuse," and "The federal government needs to cooperate with professional associations (such as establishing committees) to keep immigrants [in Canada].”

Furthermore, people made numerous comments about existing English language programs. Many respondents feel that current English classes do not meet the needs of immigrant professionals and that the wait time to enrol in Vancouver is too long. Some people specifically commented on the Host Program and funding for community organizations. Sample comments include: "Improve services for immigrants and provide help when there are difficulties," "Need more programs like the Host Program," and "Give more funds to organizations such as SUCCESS to help more immigrants systematically, provide permanent rather than temporary services." 
Some respondents felt that cooperation between the Canadian and Chinese governments could help Chinese immigrants integrate and argued that "dual citizenship” or the elimination of a visa requirement would help the free flow of Chinese immigrants.

These suggestions, while often politically naïve, reveal the multidimensional nature of the challenges facing Chinese immigrants in Vancouver.

\section{Conclusions}

The primary aim of this research project was to better understand the integration experience of Chinese immigrant residents in Vancouver circa 2004-05 and to infer the prospects of their staying or moving in the future. In particular, we surveyed that portion of the Chinese Vancouver immigrant community that would be most prone to move. Our Web-based survey, supplemented with in-person questionnaires, produced 322 respondents in the economically active group (20-65) who had high levels of education and putatively good English language skills. In addition, those surveyed were relatively recent arrivals (average 7 years in residence), predominantly from Mainland China, who were predominately married with a permanent residency status in Canada. Given this background we asked how well integrated this most recent Chinese immigrant group felt in Vancouver with respect to several key measures. Did they achieve their original goals prior to moving, and if not, what were the perceived impediments?

This surveyed resident group definitely had a long-term time horizon if we reflect on their motivations to emigrate to Vancouver. They came to Canada to become Canadian citizens, enjoy the natural environment and educate their children. Superficially these motivations appear to reflect the traditional goals of Canada's past immigrants whose intention was to presumably remain permanently in Canada. However, there exists another interpretation that is more consistent with the work of DeVoretz, Ma and Zhang (2003), which suggests that these motivations are those of sojourner immigrants who, when faced with short-term economic exigencies, may later be tempted to leave Vancouver.

The key sequence of events in the triangular migration model are the arrival of immigrants to an entrepôt country such as Canada who then begin to equip themselves with subsidized education and citizenship to hedge against future movement. This interpretation 
mirrors the findings for the surveyed Vancouver Chinese immigrant group. The necessary conditions for the triangle model to hold (citizenship acquisition and human capital accumulation) are fulfilled by many of the Chinese residents in Vancouver. However, if these necessary conditions are supplemented by weak (strong) economic outcomes in Canada (China or the rest of the world) then later onward movement will (not) occur to complete the triangle.

In fact, the reported poor employment prospects of Chinese immigrants in Vancouver, the devaluation of both their acquired Chinese education and their labour market experience and finally their low incomes all fulfill the necessary conditions for this group to move on as predicted by the triangular model. Faced with these dire economic circumstances these surveyed Chinese immigrants in Vancouver did exactly what the triangular model would predict. They invested in themselves with subsidized public goods with $70 \%$ of the adults reporting further language training, acquiring citizenship and educating their children. Thus, this penultimate prediction of the triangular model of extensive human capital acquisition would suggest that our surveyed Chinese immigrants experienced dissatisfaction with Canada and prepared themselves to move on. In fact 50\% of the respondents felt they were worse off in Vancouver than in China. Thus, we predict that both the necessary and sufficient conditions exist for a continued large-scale emigration of the post-1998 Chinese immigrant arrivals as earlier reported by Abdurrahmna and Robinson (2006). ${ }^{18}$

This study argues that successful integration into Vancouver of Chinese immigrants depends on their ability to realize their initial goals. An analysis of our econometric results indicates marital status, obtaining at least one degree in Canada and having a high income all increased the respondent's likelihood of realizing their goals and being socially satisfied while in Vancouver. ${ }^{19}$ This increased satisfaction will presumably enhance the probability that recent Chinese immigrants will stay in Vancouver. It is important to note that none of these conditioning factors, except possibly the educational location of their highest degree, is amenable to Canadian policy makers’ actions.

\footnotetext{
${ }^{18}$ They report that up to $40 \%$ of the working age immigrants from Hong-Kong to Canada have left Canada.

${ }^{19}$ Being single reduced the log odds of realizing their goals while the opposite was true for their degree of social satisfaction in Canada.
} 
Moreover, for those who have not achieved their goals and presumably would be more likely to leave, only an increase in household income increases their log odds of feeling optimistic about achieving their goals in the near future. Again, this variable is not directly amenable to public policy action. However, government action to expedite credential recognition could increase both their employment prospects and their eventual income. Thus, there appear to be two indirect policy measures (credential recognition and Canadian educational bridging) available to stem the tide of pessimism of this group with respect to achieving their goals. However, without credential recognition or local educational bridging we should expect a continued exodus of Vancouver Chinese immigrants in the near future. 


\section{Appendix A Variable Definitions For Logit Analysis}

Variable Name

Gender

Age

Marital Status

Education

Canadian Education

Length of Stay

Income

SSTNCA
Variable Definition

Male or Female

Respondent's age

Marital Status

Respondent's Highest level

Location of Highest Degree

Months since arrival

Household Income in intervals

Compared to China how is

Your social life in Canada?

\section{Operational Definition}

Male $=1$ Female $=2$

Age $=$ Midpoint of interval

Single $=1$ Married $=2$

Separated $=3$ Divorced $=4$ Widowed $=5$ Common $=6$

High school $=1$ H.S. $=2$

Diploma $=3 \mathrm{BA}=4 \mathrm{MA}=5$

Ph.d=6

2=Canada $1=$ China

Other $=0$

Midpoint of interval

Much Better $=1$ Better $=1$ Same $=2$, Worse $=3$ Much Worse $=3$ 


\section{References}

Abdurrahmna, A., \& Robinson, C. (2006). Return and outward migration among working age men. Analytical Studies Research Paper Series. Ottawa: Statistics Canada, Catalogue Number, 11F0019MIE-No. 273.

Citizenship and Immigration Canada. (1999). The economic performance of immigrants: Immigration category perspective. IMDB Profile Series.

Biser, M., DeVoretz, D., \& Pivnenko, S. (2005). The economic experiences of refugees in Canada. In P.Waxman and V. Colic-Peisker (Eds.) Homeland Wanted: Interdisciplinary perspective on refugee settlement in the West (pp.1-21) New York: Nova Science Publishers.

Borjas, G., \& Bratsberg, B. (1996). Who leaves? The out migration of the foreign-born. Review of Economics and Statistics, 78 (1), 165-176.

DeVoretz, D. J., Ma, J., \& Zhang, K. (2003). Triangular human capital flows: Some empirical evidence from Hong Kong. In J.G. Reitz (Ed.), Host societies and the reception of immigrants (pp. 469-92). San Diego: Center for U.S.-Mexican Studies, University of California.

DeVoretz, D. J., \& Pivnenko, S. (2006). The economics of Canadian citizenship. Journal of International Migration and Integration, 6 (3/4), 435-468.

Grubel, H., \& Scott, A. (1966). International flow of human capital. American Economic Review Papers and Proceedings, 56 (1/2), 268-274.

Kotkin, J. (1993). Tribes: How race, religion, and identity determine success in the global economy. New York: Random House.

Ley, D., \& Kobayashi, A. (2005). Back in Hong Kong: Return migration or transnational sojourn? RIIM Working Paper Series No. 05-09. Vancouver Centre of Excellence.

Li, P. S. (1998). The Chinese in Canada. Don Mills: Oxford University Press.

Ma, Z., \& Tian, Z. (2006). Explaining socio-economic well-being of immigrants and returned migrants: An econometric analysis of the Hong Kong and Canadian 2001 censuses. RIIM Working Paper Series No. 06-01. Vancouver Centre of Excellence.

Statistics Canada. (2003). 2001 Census: Analysis series. Ottawa: Canada.

Tseng, Y. F. (2001). New patterns of Taiwanese emigration: Capital-linked migration and its importance for economic development. In C. Aspalter (Ed.), Understanding modern Taiwan: Essays in economics, politics and social policy. Aldershot, Hampshire: Ashgate.

Vanderkamp, J. (1968). Interregional mobility in Canada: A study of the time pattern of migration. The Canadian Journal of Economics, 1 (3), 595-608.

Wallis, D. (1998). Beijing makes it happen. Vis-à-Vis Fall, 4-8.

Wong, S. L. (1992). Emigration and stability in Hong Kong. Hong Kong: The University of Hong Kong. 